\title{
Parecoxib sodium reduces the need for opioids after tonsillectomy in children: a double-blind placebo-controlled randomized clinical trial
}

\section{Le parécoxib sodique réduit le besoin d'opioïdes après une amygdalectomie chez l'enfant: une étude clinique randomisée contrôlée par placebo à double insu}

\author{
Xiuze Li, MD · Mengjun Zhou, MD · Qing Xia, MD · Juan Li, MD \\ Received: 9 April 2015/Revised: 14 September 2015/Accepted: 3 December 2015/Published online: 18 December 2015 \\ (C) Canadian Anesthesiologists' Society 2015
}

\begin{abstract}
Objective Postoperative pain is a common phenomenon after pediatric tonsillectomy. This prospective randomized double-blind placebo-controlled clinical trial was performed to evaluate the analgesic efficacy of intravenous parecoxib sodium in children undergoing tonsillectomy.
\end{abstract}

Methods Sixty children (American Society of Anesthesiologists physical status I-III, aged three to seven years, and scheduled to undergo elective tonsillectomy under general anesthesia) were randomly allocated into one of two groups to receive intravenous parecoxib sodium $1 \mathrm{mg} \cdot \mathrm{kg}^{-1}$ (Group P, $n=30$ ) or the same volume of saline (Group $S, n=30$ ) just after induction of general anesthesia. Between-group comparisons were made for the number of patients requiring rescue morphine, total number of doses of postoperative rescue morphine, time to first rescue analgesic, postoperative pain and sedation scores, and adverse effects.

Results Rescue morphine was given to more children in Group $S(25 / 30,83 \%)$ than in Group $P(17 / 30,57 \%)$ [relative risk $(R R), 1.5 ; 95 \%$ confidence interval $(C I), 1.0$ to 2.1; $P=0.024]$. The mean (SD) time to first rescue analgesic was shorter in Group $S$ than in Group P [132

This article is accompanied by an editorial. Please see Can J Anesth 2016; 63: this issue.

X. Li, MD (ه) • Q. Xia, MD · J. Li, MD

Department of Anesthesiology, Mianyang Central Hospital,

12 Changjia Lane, Mianyang 621000, Sichuan, China

e-mail: 1xz123@126.com

M. Zhou, MD

Department of Health Statistics, Mianyang Central Hospital, Mianyang, Sichuan, China
(54) $\min$ vs 193 (78) min, respectively; mean difference, 61; 95\% CI, 26.6 to 96.1; $P=0.001]$. The median (interquartile range [IQR]) Children's Hospital of Eastern Ontario Pain Scale scores in the postanesthesia care unit were lower in Group $P$ than in Group $S$ (7 [5-8] vs 9 [8-11], respectively; $P=0.001)$. The incidence of postoperative nausea and vomiting (PONV) was higher in Group $S$ than in Group P [11/30 (37\%) vs 4/30 (13\%), respectively; $R R, 2.8$; $95 \% C I, 1.0$ to $7.7 ; P=0.037]$.

Conclusions A single intravenous injection of parecoxib sodium $1 \mathrm{mg} \cdot \mathrm{kg}^{-1}$ after anesthesia induction is an effective method for the control of postoperative pain. It provides a morphine-sparing effect, prolongs the time to first rescue analgesic, and reduces PONV in children undergoing tonsillectomy.

\section{Résumé}

Objectif La douleur postopératoire est un phénomène courant après une amygdalectomie pédiatrique. Cette étude clinique prospective randomisée contrôlée par placebo et à double insu a été réalisée afin d'évaluer l'efficacité analgésique du parécoxib sodique intraveineux chez des enfants subissant une amygdalectomie.

Méthode Soixante enfants (statut physique I-III selon la classification de l'American Society of Anesthesiologists, âgés de trois à sept ans et devant subir une amygdalectomie non urgente sous anesthésie générale) ont été aléatoirement alloués à l'un de deux groupes. Le groupe $P(n=30)$ a reçu $1 \mathrm{mg} \cdot \mathrm{kg}^{-1}$ de parécoxib sodique intraveineux, alors que le groupe $S(n=30)$ a reçu le même volume de sérum physiologique juste après l'induction de l'anesthésie générale. Des comparaisons intergroupes ont été effectuées pour les patients nécessitant de la morphine en sauvetage, le nombre total de doses de 
morphine en sauvetage, le temps jusqu'à administration du premier analgésique de sauvetage, les scores de douleur postopératoire et de sédation, et les effets néfastes.

Résultats Davantage d'enfants du groupe $S$ ont reçu des doses de morphine en sauvetage (25/30, $83 \%)$ que d'enfants du groupe $P(17 / 30,57 \%)$ [risque relatif $(R R)$, 1,5; intervalle de confiance (IC) $95 \%, 1,0$ à 2,1; $P=$ 0,024]. Le temps moyen (ÉT) jusqu'à administration du premier analgésique de sauvetage était plus court dans le groupe $S$ que dans le groupe P [132 (54) min vs 193 (78) min, respectivement; différence moyenne, 61; IC $95 \%$, 26,6 à 96,1; $P=0,001]$. Les scores médians (écart interquartile [ÉIQ]) sur l'échelle de douleur du Centre hospitalier pour enfants de l'est de l'Ontario en salle de réveil étaient plus bas dans le groupe $P$ que dans le groupe $S$ (7 [5-8] vs 9 [8-11], respectivement; $P=0,001)$. L'incidence de nausées et vomissements postopératoires (NVPO) était plus élevée dans le groupe $S$ que dans le groupe $P[11 / 30(37 \%)$ vs $4 / 30$ (13\%), respectivement; RR, 2,8; IC $95 \%, 1,0$ à 7,7; $P=0,037]$.

Conclusion Une injection intraveineuse unique de 1 $m g \cdot \mathrm{kg}^{-1}$ de parécoxib sodique après l'induction de l'anesthésie constitue une méthode efficace de contrôle de la douleur postopératoire. Cette méthode procure un effet d'épargne morphinique, prolonge l'intervalle jusqu'à administration du premier analgésique en sauvetage et réduit les NVPO chez les enfants subissant une amygdalectomie.

Tonsillectomy is one of the most frequent surgeries performed in children. ${ }^{1}$ Postoperative pain control following tonsillectomy is still a great challenge to anesthesiologists. ${ }^{2}$ Even though opioid derivatives such as morphine are widely used for the management of pain after tonsillectomy, opioid consumption is positively correlated with adverse effects such as postoperative nausea and vomiting (PONV) and sedation. ${ }^{3}$ Opioids may depress ventilation and lead to airway obstruction, ${ }^{4}$ which is very dangerous during the recovery period after tonsillectomy, especially in children with a history of obstructive sleep apnea (OSA). Non-selective nonsteroidal anti-inflammatory drugs (NSAIDS), such as ketoprofen, are frequently used for analgesia in children undergoing tonsillectomy. ${ }^{5}$ Nevertheless, ketoprofen increases the risk of postoperative bleeding, ${ }^{6}$ and post-tonsillectomy hemorrhage may be a life-threatening complication. ${ }^{7}$ Parecoxib sodium is an injectable cyclooxygenase-2 (COX-2) selective inhibitor that does not inhibit platelet cyclooxygenase-1. Consequently, it does not inhibit the aggregation of platelets and may be associated with less postoperative bleeding than other non-selective NSAIDS. ${ }^{8}$ It is often administered for the management of postoperative pain in adults and is generally well tolerated. ${ }^{9}$

The primary objective of the present study was to evaluate the opioid-sparing effect of a single intravenous dose of parecoxib sodium in children undergoing tonsillectomy. The secondary objective of the trial was to assess the common adverse effects. We hypothesized that parecoxib sodium would decrease morphine requirements and adverse effects after tonsillectomy in children.

\section{Methods}

This study was approved by the Ethics Committee of Mianyang Central Hospital, Sichuan, China (Ethics Committee No. 2014010, Chairperson Prof L Cheng) on January 3, 2014 and registered at the Chinese Clinical Trial Registry (ChiCTR-TRC-14004083). With the approval of the Ethics Committee and the written informed consent of their parents or guardians, sixty children were randomly enrolled into one of two groups. Inclusion criteria were children aged three to seven years, American Society of Anesthesiologists (ASA) physical status I to III, and scheduled for elective tonsillectomy, with or without adenoidectomy under general anesthesia. Children were excluded from the study if they had an allergy to the medications, serious cardiovascular disease, liver or kidney dysfunction, coagulation disorders, asthma, or an upper respiratory infection. A computer-generated random number table was used for randomization to the two study groups, parecoxib sodium (Group P) or placebo (saline; Group S). Indications for tonsillectomy included obstructive sleep apnea (OSA), chronic tonsillitis, or a combination of both. The random allocation numbers were concealed in sealed opaque envelopes and opened sequentially after consent was obtained from children or parents. Participants, investigators, and evaluators were blinded to the group assignment. On the morning of surgery, a nurse (who was not involved in any other part of the study) prepared the active drug or placebo in a $5 \mathrm{~mL}$ syringe, and an anesthesiologist (who was blinded to its contents) administered the dosage.

All children were required to fast from solid foods for six hours before anesthesia but were allowed to drink clear fluids until two hours before anesthesia. The children did not receive premedication. While on the ward, an intravenous catheter was inserted into the dorsum of each child's hand. The monitoring system consisted of pulse oximetry, noninvasive arterial pressure, electrocardiography, and end-tidal carbon dioxide. Anesthesia was induced with a bolus injection of propofol $3 \mathrm{mg} \cdot \mathrm{kg}^{-1}$ and remifentanil 
Figure CONSORT

flowchart of patients through the clinical trial

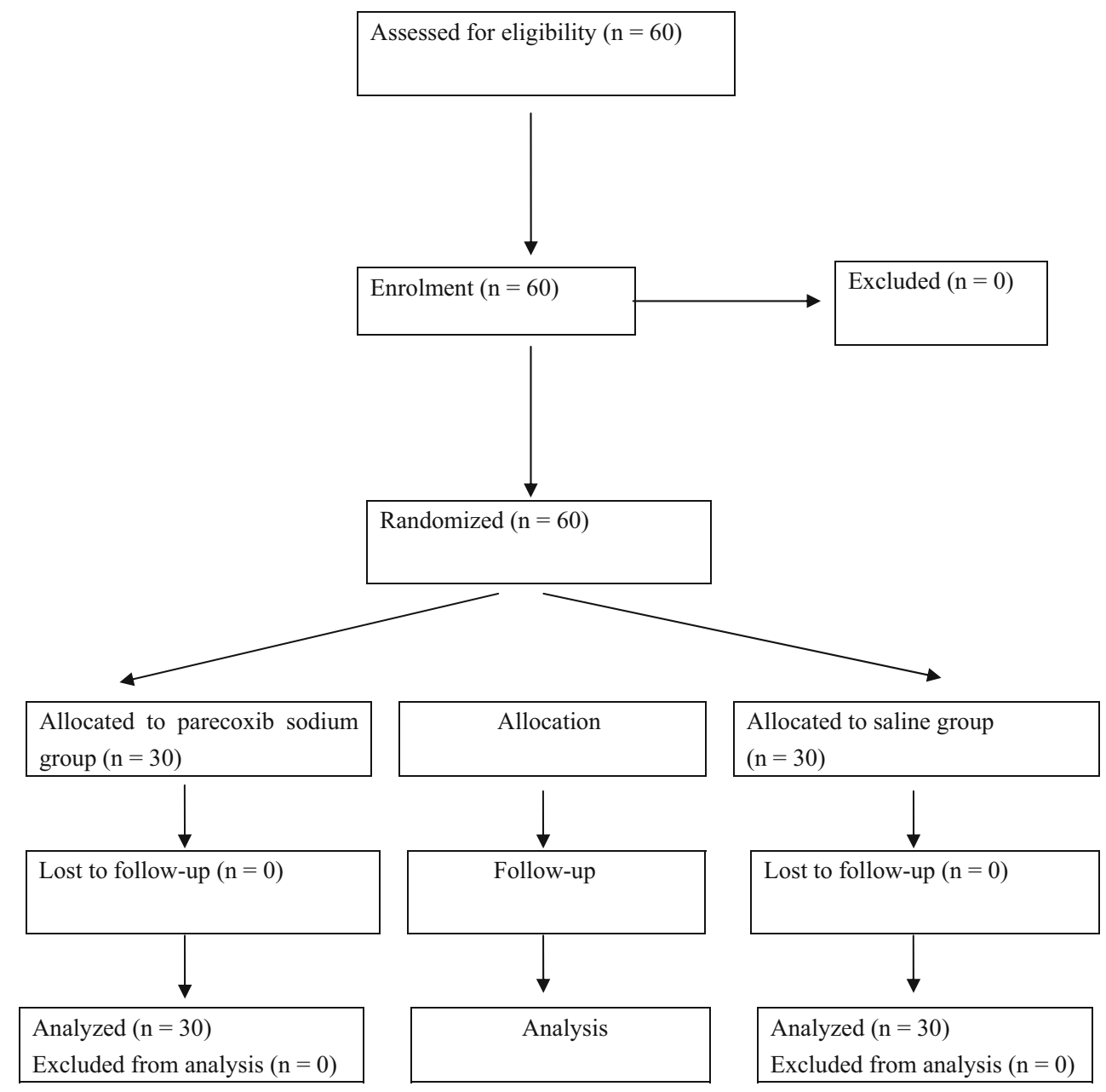

$1 \mu \mathrm{g} \cdot \mathrm{kg}^{-1}$. Cisatracurium $0.15 \mathrm{mg} \cdot \mathrm{kg}^{-1}$ was used to facilitate intubation. Just after induction of general anesthesia, patients in the intervention group received parecoxib sodium $1 \mathrm{mg} \cdot \mathrm{kg}^{-1}$ (maximum $40 \mathrm{mg}$ ) $i v$, and patients in the saline group received the same volume of saline. Mechanical ventilation was administered in all children to maintain an end-tidal $\mathrm{CO}_{2}$ level of 30-40 $\mathrm{mmHg}$. All children received lactated Ringer's solution at a rate of $5 \mathrm{~mL} \cdot \mathrm{kg}^{-1} \cdot \mathrm{hr}^{-1}$. Anesthesia was maintained with 1$2 \%$ sevoflurane in an oxygen-air mixture $\left(\mathrm{F}_{\mathrm{I}} \mathrm{O}_{2} \quad 0.5\right)$ and a continuous infusion of remifentanil $0.1-0.3 \mu \mathrm{g} \cdot \mathrm{kg}^{-1} \cdot \mathrm{min}^{-1}$ to maintain the arterial pressure and heart rate of each child within $30 \%$ of the baseline values. Dexamethasone 0.5 $\mathrm{mg} \cdot \mathrm{kg}^{-1}$ (maximum $10 \mathrm{mg}$ ) was given intravenously at the end of anesthesia induction to prevent PONV. The same surgeon performed the tonsillectomy in all of the children using the dissection technique. At the end of the surgery, the anesthetics were discontinued and a bolus of morphine 50 $\mu \mathrm{g} \cdot \mathrm{kg}^{-1}$ was given to all of the children for control of postoperative pain. Neuromuscular block was monitored by means of a TOF-Watch ${ }^{\circledR} \mathrm{SX}$ peripheral nerve stimulator
(Organon, Dublin, Ireland). Muscle relaxation was reversed with neostigmine $0.04 \mathrm{mg} \cdot \mathrm{kg}^{-1}$ and atropine $0.02 \mathrm{mg} \cdot \mathrm{kg}^{-1}$. The endotracheal tube was removed when the children opened their eyes and showed purposeful movements. Vital signs during surgery were recorded.

After surgery, the children were taken to the postanesthesia care unit (PACU). All the patients received oxygen via nasal oxygen catheter. Postoperative pain, sedation, heart rate, arterial blood pressure and oxygen saturation were assessed every five minutes for the first fifteen minutes and every 15 min thereafter in the PACU. The children were also evaluated on arrival to the surgical ward and at four, eight, 12, 16, 20, and $24 \mathrm{hr}$ on the ward. Postoperative pain was estimated by using the Children's Hospital of Eastern Ontario Pain Scale (CHEOPS). ${ }^{10}$ Postoperative sedation was evaluated as follows: 1 = anxious, agitated, and restless; $2=$ cooperative, oriented, and tranquil; $3=$ responds to commands only; $4=$ asleep, brisk response to light glabellar tap or loud auditory stimulus; $5=$ asleep, sluggish response to light glabellar tap or loud auditory 
Table 1 Patients' demographics, indications for tonsillectomy, duration of surgery and anesthesia, type of surgery, and remifentanil dose in children who received parecoxib sodium (Group P) or saline (Group S)

\begin{tabular}{lll}
\hline & $\begin{array}{l}\text { Group P } \\
(n=30)\end{array}$ & $\begin{array}{l}\text { Group S } \\
(n=30)\end{array}$ \\
\hline Age $(\mathrm{yr})$ & $5(1.4)$ & $5.1(1.3)$ \\
Weight $(\mathrm{kg})$ & $19.8(5.6)$ & $20.7(6.1)$ \\
Sex (male/female) & $18 / 12$ & $17 / 13$ \\
ASA physical status (I/II/III) & $8 / 7 / 15$ & $9 / 8 / 13$ \\
Indications for tonsillectomy & & \\
OSA & 12 & 11 \\
Infection & 15 & 17 \\
Combination & 3 & 2 \\
Duration of surgery (min) & $37(6.1)$ & $36.1(6.8)$ \\
Duration of anesthesia (min) & $53(6.5)$ & $50.5(7.5)$ \\
Type of surgery (T/T+A) & $5 / 25$ & $4 / 26$ \\
Remifentanil dose & $0.21(0.09)$ & $0.21(0.07)$ \\
$\quad\left(\mu \mathrm{g} \cdot \mathrm{kg}^{-1} \cdot \mathrm{min}^{-1}\right)$ & & \\
\hline
\end{tabular}

Data are presented as mean $(\mathrm{SD})$ or number. ASA $=$ American Society of Anesthesiologists; OSA = obstructive sleep apnea; $\mathrm{T}=$ tonsillectomy; $\mathrm{T}+\mathrm{A}=$ tonsillectomy and adenoidectomy

stimulus; $6=$ asleep, no response. ${ }^{11}$ The highest pain and sedation scores in the PACU and the ward were recorded for the final analysis. The children received intravenous morphine $25 \mu \mathrm{g} \cdot \mathrm{kg}^{-1}$ as rescue medication if they had a CHEOPS $\geq 8$. This dose was repeated after five minutes if the child was still in pain. After the child was transferred to the ward or discharged home, paracetamol $15 \mathrm{mg} \cdot \mathrm{kg}^{-1}$ orally every six hours and tramadol $2 \mathrm{mg} \cdot \mathrm{kg}^{-1}$ every eight hours as needed were administered for the management of postoperative pain. Data regarding rescue medication were recorded, including the number of patients receiving postoperative analgesic, the total number of doses and amount of postoperative rescue morphine, and the time to first rescue analgesic.

The duration of surgery, time of anesthesia (from the start of induction to the end of anesthesia), and duration of stay in the PACU were noted. Data regarding adverse effects that occurred in the PACU and on the ward were also recorded, including PONV, airway obstruction, oxygen desaturation (oxygen saturation $<90 \%$ ), or pruritus. Postoperative nausea and vomiting was treated with ondansetron $0.1 \mathrm{mg} \cdot \mathrm{kg}^{-1}$. Children were transferred to the surgical ward when hemodynamically stable and fully awake with no pain or vomiting. Patients were discharged home after 24-hr observation on the ward.

\section{Statistical analysis}

The primary outcome was the number of children who required rescue morphine in the PACU. Secondary outcome variables were the total number of doses of rescue morphine, the time to first rescue analgesic, postoperative pain and sedation scores, and postoperative adverse effects such as PONV, pruritus, and respiratory depression. The sample size calculation was based on a previous study in which $90 \%$ of children given saline required rescue analgesics in the PACU after tonsillectomy. ${ }^{12}$ A $30 \%$ reduction in the requirement for analgesics in the parecoxib sodium group was considered to be clinically significant. We calculated that 25 children were required in each group with an alpha of 0.05 and a power of 0.8 . Nevertheless, we recruited 30 patients in each group to account for possible dropouts. Normally distributed continuous variables were described as mean (SD), while non-normally distributed continuous variables were described as median (interquartile range [IQR]). Categorical variables were described as number

Table 2 The number of children receiving rescue morphine, total number of doses and mean amount of postoperative rescue morphine, PACU and first rescue analgesic times, and the CHEOPS and sedation scores in patients who received parecoxib sodium (Group P) or saline (Group S)

\begin{tabular}{|c|c|c|c|c|}
\hline & Group P $(n=30)$ & Group S $(n=30)$ & $\begin{array}{l}\text { Relative risk }(95 \% \mathrm{CI}) \text { or difference } \\
\text { in means }(95 \% \mathrm{CI})\end{array}$ & $P$ value \\
\hline $\begin{array}{l}\text { Number of children who received rescue } \\
\text { morphine }\end{array}$ & $17 / 30(57 \%)$ & $25 / 30(83 \%)$ & $1.5(1.0$ to 2.1$)$ & 0.024 \\
\hline Total number of doses of rescue morphine & $1[0-1]$ & $1[1-2]$ & & 0.003 \\
\hline Morphine given in PACU $\left(\mu \mathrm{g} \cdot \mathrm{kg}^{-1}\right)$ & $36.5(30.2)$ & $55.8(32.6)$ & $19.3(3.7$ to 38.1$)$ & 0.017 \\
\hline PACU time (min) & $96(32)$ & $91(18)$ & $5(-8.4$ to 18.7$)$ & 0.54 \\
\hline First rescue analgesic time $(\mathrm{min})$ & $193(78)$ & $131.7(54.4)$ & $61.3(26.6$ to 96.1$)$ & 0.001 \\
\hline PACU CHEOPS & $7[5-8.3]$ & $9[7.8-11]$ & & 0.001 \\
\hline Ward CHEOPS & $5[4-7]$ & $5[5-7.3]$ & & 0.29 \\
\hline PACU sedation scores & $2[2-3]$ & $3[2-4]$ & & 0.032 \\
\hline Ward sedation scores & $2[2-3]$ & $2[2-3]$ & & 0.43 \\
\hline
\end{tabular}

Data are mean (SD), median [interquartile range], or number (percentage). Relative risks are computed for the saline group compared with the parecoxib group. CHEOPS $=$ The Children's Hospital of Eastern Ontario Pain Scale; CI = confidence interval; PACU = postanesthesia care unit 
Table 3 Incidence of side effects in children who received parecoxib sodium (Group P) or saline (Group S)

\begin{tabular}{lllll}
\hline & Group P $(n=30)$ & Group S $(n=30)$ & Relative risk (95\% CI) & $P$ value \\
\hline PONV & $4 / 30(13 \%)$ & $11 / 30(37 \%)$ & $2.8(1.0$ to 7.7$)$ & 0.037 \\
Laryngospasm & $1 / 30(3 \%)$ & $0 / 30(0)$ & - & 1.0 \\
Airway obstruction & $1 / 30(3 \%)$ & $3 / 30(10 \%)$ & $3.0(0.3$ to 27.2$)$ \\
Oxygen desaturation & $0 / 30(0)$ & $1 / 30(3 \%)$ & - & 0.31 \\
Pruritus & $2 / 30(7 \%)$ & $4 / 30(13 \%)$ & $2.0(0.4$ to 10.1$)$ & 1.0 \\
\hline
\end{tabular}

Values are expressed as number of patients (percentage of patients). Relative risks are computed for the saline group compared with the parecoxib group. $\mathrm{CI}=$ confidence interval; $\mathrm{PONV}=$ postoperative nausea and vomiting

(percentage). The differences between the groups were analyzed using analysis of variance, Mann-Whitney $U$ test, or Chi square test, as appropriate (Fisher's exact test was used instead of the Chi square test when expected cell counts were $\leq 5$ ). All reported $P$ values are two-sided. SPSS $^{\circledR} 17.0$ software (SPSS Inc., Chicago, IL, USA) was used for statistical analysis.

\section{Results}

Sixty children were selected and all patients completed the present study for the final analysis (Figure).

The two groups were similar with respect to age, weight, sex, ASA physical status, indications for tonsillectomy, duration of surgery or anesthesia, type of surgery, and remifentanil dose (Table 1).

Table 2 shows the number of patients receiving rescue morphine, the total number of doses, and the mean amount of rescue morphine in the two groups. Significantly fewer children in Group $\mathrm{P}$ required postoperative rescue morphine compared with Group S. The total number of doses and the mean amount of rescue morphine for the patients in Group $\mathrm{P}$ were also significantly lower than those in Group $\mathrm{S}$. The time to first rescue analgesic was significantly shorter in Group $\mathrm{S}$ than in Group $\mathrm{P}$. The number of children who received rescue paracetamol and tramadol on the ward was not different between the two groups. The CHEOPS and sedation scores of the two groups are shown in Table 2. In the PACU, the CHEOPS scores of patients in Group $\mathrm{P}$ were significantly lower than in Group S. Sedation scores in Group P were also lower than those in Group S. The CHEOPS and sedation scores on the ward were similar between the two groups.

Postoperative complications of the two groups are presented in Table 3. The incidence of PONV was significantly higher in Group $S$ compared with that in Group P. The incidence of laryngospasm, airway obstruction, oxygen desaturation, and pruritus were comparable between the two groups. None of the children required reoperation because of bleeding during the entire postoperative period.

\section{Discussion}

This study showed that a single intravenous injection of parecoxib sodium $1 \mathrm{mg} \cdot \mathrm{kg}^{-1}$ after anesthesia induction reduces pain and sedation scores compared with saline, provides a morphine-sparing effect, prolongs the time to first rescue analgesic, and reduces the incidence of postoperative nausea and vomiting. Our study indicated that $83 \%$ of the children who were given saline required rescue morphine after tonsillectomy in the PACU, which is a lower result than observed in other studies. ${ }^{12,13}$ This is probably because, in our study, we gave morphine at the end of the surgery for the control of postoperative pain. This may have decreased the need for postoperative rescue analgesic.

Pain is a common symptom in children after tonsillectomy, and postoperative pain is correlated with emergence agitation, which is one of the most common clinical phenomena in children undergoing tonsillectomy. ${ }^{14}$ Effective pain treatment is therefore very important in children undergoing tonsillectomy, because it may reduce the risk of postoperative bleeding due to emergence agitation, ${ }^{15}$ and hemorrhage may be a potentially life-threatening complication. ${ }^{16}$

Reports in the literature are lacking regarding the use of preemptive parecoxib sodium in children undergoing tonsillectomy. Based on previous research by Hullett et al., ${ }^{17}$ we gave the children parecoxib sodium in a dose of $1 \mathrm{mg} \cdot \mathrm{kg}^{-1}$, which is also current practice for administering parecoxib sodium in our hospital. Parecoxib sodium was administered to the children prior to surgery because it has been shown that NSAIDS can inhibit the activation of nociceptors due to tissue damage. ${ }^{18}$ We found that intravenous parecoxib sodium had a morphine-sparing effect. Moreover, our results revealed that three of four children with PONV in the parecoxib sodium group and nine of eleven with PONV in the saline group had received rescue morphine. Therefore, in our view, the PONV observed may have been associated with the use of morphine. The incidence of PONV in our study was higher than that in the study by Sheeran et al. ${ }^{19}$ This is possibly because the investigators in that study used both 
dexamethasone and ondansetron for the prevention of PONV, while we used only dexamethasone in our study. As there is a high risk of PONV with tonsillectomy, an incidence ranging from $40-73 \%,{ }^{20}$ two antiemetics may be more appropriate for children undergoing tonsillectomy.

Rofecoxib is also a selective COX-2 inhibitor, but a previous study showed that it did not decrease opioid use in children undergoing tonsillectomy. ${ }^{19}$ This is probably because the oral formulation of rofecoxib has a delayed absorption, i.e., the time of peak effect is longer than that of parecoxib sodium, ${ }^{21,22}$ and the researchers assessed the effect of rofecoxib on opioid consumption only in the PACU.

Our study had a few limitations. The use of CHEOPS for the assessment of postoperative pain in children aged three to seven years is controversial, as some authors think that the CHEOPS does not correlate with self-reported pain measures in children. ${ }^{23}$ The use of remifentanil for tonsillectomy, rather than fentanyl, may be associated with higher postoperative pain scores and may therefore need better prophylactic analgesic regimens for control of postoperative pain. ${ }^{24}$ Nevertheless, the use of morphine at the end of the surgery in our study may have decreased the requirement for postoperative rescue analgesics. Since there have been concerns regarding cardiovascular events associated with the use of rofecoxib and valdecoxib (the active metabolite of parecoxib), ${ }^{25}$ the safety of parecoxib sodium in pediatric patients should be evaluated in larger clinical trials. Finally, we did not compare blood loss between the two groups because we think parecoxib sodium has a minimal effect on platelet function due to its COX-2 selectivity. Our study was not powered to detect a difference in rebleeding after tonsillectomy. Further studies are needed to refine the optimal dose of parecoxib sodium for analgesia in children undergoing tonsillectomy. Further studies should also be conducted to determine whether preemptive use of intravenous acetaminophen in children undergoing tonsillectomy leads to the same effect as parecoxib sodium.

In conclusion, a single intravenous injection of parecoxib sodium $1 \mathrm{mg} \cdot \mathrm{kg}^{-1}$ after anesthesia induction decreases morphine requirements, prolongs the time to first rescue analgesic, and reduces adverse effects after tonsillectomy in children.

Author contributions: Xiuze $L i$ was involved in drafting the article and in the conception and design of the study. Mengjun Zhou was involved in the analysis and interpretation of data. Qing Xia was involved in revising the article critically for important intellectual content. Juan $L i$ was involved in the acquisition of data.

Acknowledgement The authors acknowledge the staff of the PACU at Mianyang Central Hospital for their friendly assistance with the study.
Financial support and sponsorship None.

Conflicts of interest None declared.

\section{References}

1. Baugh RF, Archer SM, Mitchell RB, et al. Clinical practice guideline: tonsillectomy in children. Otolaryngol Head Neck Surg 2011; 144(1 Suppl): S1-30.

2. Kokki H, Nikanne E, Aho M, Virtaniemi J. Pain intensity after laseruvulopalatoplasty and tonsillectomy. Otolaryngol Head Neck Surg 2003; 128: 273-9.

3. Marret E, Kurdi $O$, Zufferey P, Bonnet $F$. Effects of nonsteroidal antiinflammatory drugs on patient-controlled analgesia morphine side effects: meta-analysis of randomized controlled trials. Anesthesiology 2005; 102: 1249-60.

4. Mukherjee K, Esuvaranathan V, Streets C, Johnson A, Carr AS. Adenotonsillectomy in children: a comparison of morphine and fentanyl for peri-operative analgesia. Anaesthesia 2001; 56: 1193-7.

5. Kokki $H$. Ketoprofen pharmacokinetics, efficacy, and tolerability in pediatric patients. Paediatr Drugs 2010; 12: 313-29.

6. Kokki H, Salonen A. Comparison of pre- and postoperative administration of ketoprofen for analgesia after tonsillectomy in children. Paediatr Anaesth 2002; 12: 162-7.

7. Windfuhr JP, Schloendorff $G$, Baburi D, Kremer B. Lifethreatening posttonsillectomy hemorrhage. Laryngoscope 2008; 118: 1389-94.

8. Graff J, Arabmotlagh M, Cheung R, Geisslinger G, Harder S. Effects of parecoxib and dipyrone on platelet aggregation in patients undergoing meniscectomy: a double-blind, randomized, parallel-group study. Clin Ther 2007; 29: 438-47.

9. Papadima A, Lagoudianakis EE, Antonakis PT, et al. Parecoxib vs. lornoxicam in the treatment of postoperative pain after laparoscopic cholecystectomy: a prospective randomized placebo-controlled trial. Eur J Anaesthesiol 2007; 24: 154-8.

10. Tyler DC, Tu A, Douthit J, Chapman CR. Toward validation of pain measurement tools for children: a pilot study. Pain 1993; 52 : 301-9.

11. Ramsay MA, Savege TM, Simpson BR, Goodwin R. Controlled sedation with alphaxalone-alphadolone. Br Med J 1974; 2: 656-9.

12. Erhan OL, Goksu H, Alpay C, Bestas A. Ketamine in posttonsillectomy pain. Int J Pediatr Otorhinolaryngol 2007; 71: 735-9.

13. Umuroglu T, Eti Z, Ciftci H. Yilmaz Gogus F. Analgesia for adenotonsillectomy in children: a comparison of morphine, ketamine and tramadol. Paediatr Anaesth 2004; 14: 568-73.

14. Aouad MT, Nasr VG. Emergence agitation in children: an update. Curr Opin Anaesthesiol 2005; 18: 614-9.

15. Gooden R, Tennant I, James B, et al. The incidence of emergence delirium and risk factors following sevoflurane use in pediatric patients for day case surgery, Kingston, Jamaica (Portuguese). Rev Bras Anestesiol 2014; 64: 413-8.

16. Kokki $H$. Nonsteroidal anti-inflammatory drugs for postoperative pain: a focus on children. Paediatr Drugs 2003; 5: 103-23.

17. Hullett B, Salman S, O'Halloran SJ, Peirce D, Davies K, Ilett KF. Development of a population pharmacokinetic model for parecoxib and its active metabolite valdecoxib after parenteral parecoxib administration in children. Anesthesiology 2012; 116: 1124-33.

18. Campbell WI, Kendrick R, Patterson C. Intravenous diclofenac sodium. Does its administration before operation suppress postoperative pain? Anaesthesia 1990; 45: 763-6. 
19. Sheeran PW, Rose JB, Fazi LM, Chiavacci R, McCormick $L$. Rofecoxib administration to paediatric patients undergoing adenotonsillectomy. Paediatr Anaesth 2004; 14: 579-83.

20. Elhakim M, Ali NM, Rashed I, Riad MK, Refat $M$. Dexamethasone reduces postoperative vomiting and pain after pediatric tonsillectomy. Can J Anesth 2003; 50: 392-7.

21. Scott LJ, Lamb HM. Rofecoxib. Drugs 1999; 58: 499-505.

22. Stichtenoth DO, Fro lich JC. The second generation of COX-2 inhibitors: what advantages do the newest offer? Drugs 2003; 63: 33-45.

23. Shamim F, Ullah $H$, Khan FA. Postoperative pain assessment using four behavioral scales in Pakistani children undergoing elective surgery. Saudi J Anaesth 2015; 9: 174-8.
24. Davis PJ, Finkel JC, Orr RJ, et al. A randomized, double-blinded study of remifentanil versus fentanyl for tonsillectomy and adenoidectomy surgery in pediatric ambulatory surgical patients. Anesth Analg 2000; 90: 863-71.

25. Sun SX, Lee KY, Bertram CT, Goldstein JL. Withdrawal of COX2 selective inhibitors rofecoxib and valdecoxib: impact on NSAID and gastroprotective drug prescribing and utilization. Curr Med Res Opin 2007; 23: 1859-66. 